\title{
VALOR ARQUITECTÓNICO Y SIMBÓLICO DEL PABELLÓN CENTRAL DE LA UNIVERSIDAD NACIONAL DE INGENIERIIA ${ }^{[*]}$
}

\author{
ARCHITECTURAL AND SYMBOLIC VALUE OF THE CENTRAL PAVILION OF THE NATIONAL \\ UNIVERSITY OF ENGINEERING \\ SANDRA SALAZAR BRIONES $S^{[*]}$ \\ (iD) https://orcid.org/0000-0002-6944-0149 \\ ssalazarbriones.122@gmail.com \\ Universidad Peruana de Ciencias Aplicadas (Perú) \\ Fecha de recepción: 30 de abril del 2019 \\ Fecha de aprobación: 6 de agosto del 2019
}

\section{RESUMEN}

El presente artículo permite identificar el valor simbólico y arquitectónico que tiene el Pabellón Central, el primer edificio construido en la Universidad Nacional de Ingeniería (UNI) en su nuevo local. La metodología aplicada en esta investigación está trazada por medio del análisis del contexto urbano e histórico, el estudio de las tipologías arquitectónicas y los nuevos materiales constructivos que hicieron de esta obra una de las más modernas de su tiempo. A través de la recolección de imágenes e información, se conocerá el papel que ha adquirido en la sociedad desde su origen hasta la actualidad. El objetivo de este estudio pretende contribuir en la difusión sociocultural del edificio emblemático de la UNI y evaluar el estado de su conservación actual.

\section{PALABRAS CLAVE}

Valor patrimonial; art decó; Pabellón Central UNI

\section{ABSTRACT}

This article identifies the symbolic and architectural value of the Central Pavilion. The first building built for the National Engineering University in its new premises. The methodology applied in this research is drawn through the analysis of the urban and historical context, the study of the architectural typologies and the new construction materials that made this work one of the most modern of its time. Through the collection of images and information, the role it has acquired in society from its origin to the present will be known. The objective of this study aims to contribute to the sociocultural dissemination of the emblematic building of the UNI and evaluate the state of its current conservation.

\section{KEYWORDS}

Heritage; art deco; Central Pavilion UNI

(*) El presente artículo es una síntesis del trabajo de investigación elaborado en la asignatura de Arquitectura Peruana, a cargo del Msc. Arq. José Hayakawa Casas, de la Universidad Peruana de Ciencias Aplicadas (UPC) durante el ciclo 2017-I.

$\left.{ }^{* *}\right)$ Estudiante de décimo ciclo de Arquitectura en la Universidad Peruana de Ciencias Aplicadas UPC. Tiene experiencia como practicante en el área de Subgerencia de Estudios y Proyectos de Infraestructura de la Municipalidad de San Juan de Miraflores. 


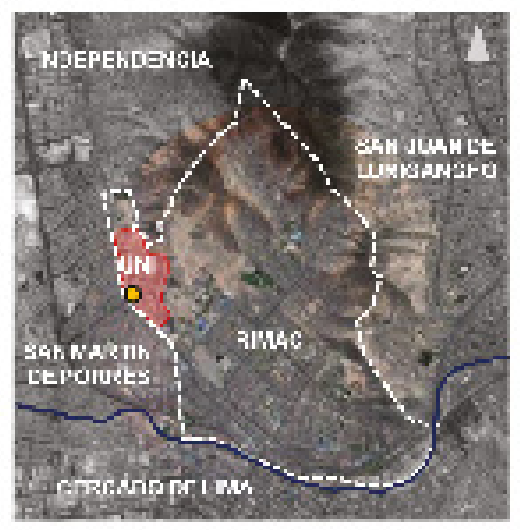

Dik. R $\cdots$

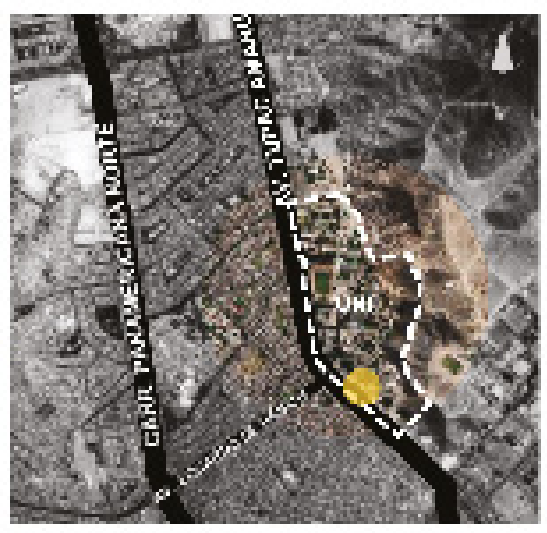

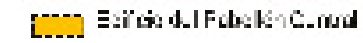

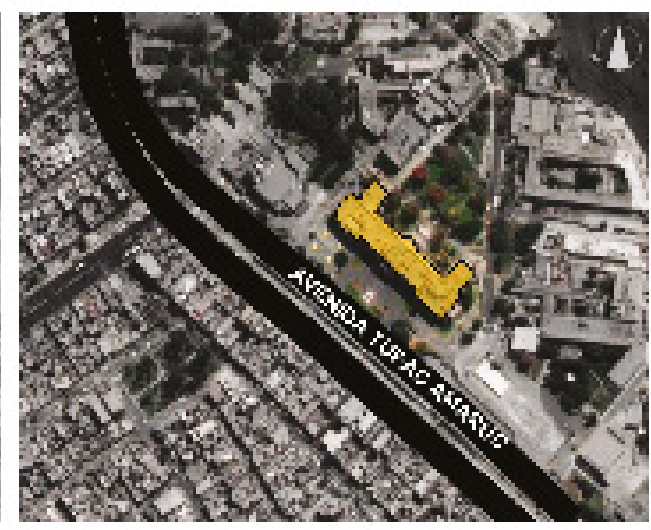

Figura 1. Vista aérea actual de ubicación del Pabellón Central. Adaptado de Google Maps, 2019.

\section{Ubicación}

Uno de los inmuebles más importantes de la UNI se encuentra localizado al norte de la capital peruana, Lima. Esta ciudad cuenta con una latitud de $12^{\circ} 02^{\prime} 35^{\prime \prime} \mathrm{S}$ y una longitud de $77^{\circ} 1^{\prime} 41^{\prime \prime}$ O. Debajo de la actual superficie urbana, se esconde una red de restos arqueológicos e históricos que manifiestan las huellas físicas, constructivas y espirituales de un mundo milenario que había estratificado la experiencia del culto de los limas, los huaris y los ichmas (Gavazzi, 2017). El Pabellón Central se ubica en el Rímac, el distrito más antiguo, histórico y monumental. Según el Instituto Nacional de Estadística (INEI, 2017, p. 29), cuenta con una población de 162897 habitantes. Limita, por el norte, con el distrito de Independencia; por el sur, con el Cercado de Lima, mediante el río Rímac; por el oeste con San Martín de Porres; y por el este con el distrito de San Juan de Lurigancho. Asimismo, la UNI se ubica en el terreno del antiguo fundo Puente Palo y está delimitada por la avenida Túpac Amaru, un antiguo camino que forma parte del recorrido del Qhapaq Ñan o Camino Inca y que conecta la costa norte con el centro de la capital, y por el cerro Arrastre (Guzmán, 2015, p. 106) (ver Figura 1).

\section{Diseño metodológico}

Esta investigación consiste en el estudio de las cualidades arquitectónicas del Pabellón Central de la UNI como expresión social de su tiempo y espacio. Para ello, se utilizó el método cualitativo, que consiste en obtener información gráfica a través de la recopilación de fotografías antiguas y actuales extraídas de libros, así como de archivos encontrados en el Centro de Historia UNI, el Prolima, el Centro de Infraestructura Universitaria (CIU), el Servicio Aerofotográfico Nacional (SAN) e imágenes tomadas durante el proceso de la investigación.

Además, para entender el aspecto simbólico, se aplicaron encuestas y se analizaron imágenes mediante el método de imaginarios urbanos de Armando Silva (2006): «Se trata de recopilar materiales sobre la ciudad que aparecen en medios masivos y en Internet y también registran hechos urbanos que se detectan en las encuestas por medio de fotografías y videos» (p. 63).

Finalmente, se realizaron entrevistas a expertos y especialistas sobre la historia de la UNI y del patrimonio arquitectónico del Perú. Por otra parte, en la investigación se analizan los aspectos constructivos-estructurales, funcionales-simbólicos y formales-espaciales con el objetivo de difundir las características arquitectónicas de la edificación 
en cuestión y para entender su función como expresión social en un territorio y tiempo específicos.

\section{Marco teórico}

En 2019, se conmemoran 74 años de la inauguración del Pabellón Central. En la actualidad, la universidad funciona como campus universitario, que a lo largo de sus 143 años de fundación se ha utilizado en la formación de los nuevos ingenieros y arquitectos del Perú.

Este local universitario alberga un conjunto de monumentos construidos en diversos periodos de la historia limeña, como la huaca UNI-Cismid y la huaca UNI-Minas (Guzmán, 2015, p. 104). Además, cuenta con arquitectura moderna, como el edificio de la Facultad de Arquitectura, Urbanismo y Artes (FAUA), diseñado por el arquitecto Mario Bianco, y el Pabellón Central, diseñado y dirigido por el arquitecto Roberto Haaker Fort. Estas edificaciones son un aporte cultural para la universidad, ya que brindan información de los acontecimientos del pasado y su conservación es responsabilidad del organismo al que pertenecen. El aprecio que evoca un monumento en la comunidad a la que es heredada se manifiesta mediante hechos que identifican a los sujetos. En el caso del patrimonio, muchos de estos hechos son sucesos del pasado que repercuten en la memoria de cada de individuo por intermedio de un recuerdo, el cual es percibido ante la presencia de un ícono. En el caso de la arquitectura, este ícono es el monumento.

Como menciona Ballart (como se cita en Hayakawa, 2012): «Cuando hablamos de patrimonio hablamos de bien y por lo tanto de valor como "aprecio hacia determinados objetos por el mérito que atesoran, por la utilidad que manifiestan, o por su aptitud para satisfacer necesidades o proporcionar bienestar"» (p. 2).

Asimismo, el patrimonio cultural se argumenta a través de sus dos vocablos, como indica Nieto (2018):

En la actualidad se entiende como Patrimonio Cultural todo tipo de manifestaciones fruto del intelecto humano, tanto de tipo tangible — mueble, paisaje natural - como intangible —el habla, las fiestas, por ejemplo-. El concepto es la suma de dos vocablos: patrimonio y cultura. El primero hace referencia a una dimensión jurídica — herencia- - y el segundo a una dimensión intangible entendido lo cultural como un sistema de creencias y significados consensuados y compartidos con una comunidad, una fábrica de significados en torno a cierto conjunto de elementos heredados. (p. 35)

Según Hayakawa (2012), el valor es entendido en sus diferentes acepciones como el "grado de utilidad o aptitud de las cosas, para satisfacer las necesidades o proporcionar bienestar o deleite [...] Alcance de la significación o importancia de una cosa, acción, palabra o frase» (p. 2). En cuanto al valor del patrimonio, Kayakawa (2012) lo divide en tres tipos:

a) Un valor de uso [...] en el sentido de pura utilidad, es decir, [...] que sirve para hacer con él [...], que satisface una necesidad material o de conocimiento o un deseo. Es la dimensión utilitaria [...].

b) Un valor formal [...] responde al hecho [...] que determinados objetos son apreciados por la atracción que despiertan a los sentidos, por el placer que proporcionan, por razón de la forma y por otras cualidades sensibles, y por el mérito que presentan.

c) Un valor simbólico-significativo [...] la consideración en que se tienen los objetos del pasado en tanto [...] presencias sustitutivas y hacen de nexo entre personas separadas por el tiempo, por lo que son testimonio de ideas, hechos y situaciones del pasado [...] (p. 2). 
devenir Vol.6, N¹2, JULIO- DICIEMBRE 2019, PP. 115-136 - EstudIOS I ISSN 2312-7562 | E-ISSN 2616-4949

UNIVERSIDAD NACIONAL DE INGENIERÍA, LIMA

doi: https://doi.org/10.21754/devenir.v6i12.746

Respecto del análisis de los tipos de valores, Cristina Nieto (2018) ofrece el siguiente punto de vista:

a) Valor de uso. Para utilidad, satisface una necesidad material, de conocimiento o deseo.

b) Valor formal. Son apreciados por la atracción en los sentidos.

c) Valor simbólico-significativo. La consideración de conservar los testimonios por tratarse de vehículos que conectan una estadía pasada con el presente. Tiene carácter rememorativo, y ayuda a entablar una relación entre las personas o el grupo humano que lo produjo y la sociedad actual.

En un bien cultural podemos encontrar uno, dos o los tres valores expuestos, y su graduación o valor principal depende subjetivamente del receptor. La significación del Patrimonio tiene una dimensión totalmente social, ya que es un valor variable depende de los sujetos, del grado de relación y apropiación del objetivo, de la estimación por el mismo; y a su vez todo depende de los diferentes sujetos o entornos en los que se ubica el susodicho bien patrimonial. (p. 60)

Sobre la importancia de preservar edificios y grandes construcciones, esta nace de la necesidad de recordar un evento importante que sucedió en el sitio, o a las personas que lo constituyeron, y la razón por la cual se edificó. Por ejemplo, se tiene al famoso Arco del Triunfo de París, que fue construido entre 1806 y 1836 por orden del emperador Napoleón I. La finalidad de esta construcción fue conmemorar la victoria de la batalla de Austerlitz, en la que se enfrentó el ejército francés con el ruso-austriaco (Gambetta, 2018, p. 13).

Asimismo, no hay que olvidar que el patrimonio puede abarcar otros conceptos más contemporáneos que permiten la interacción con los usuarios y que contribuyen a las prácticas sociales.

De esta manera, se considera que el patrimonio, ya sea tangible o intangible, es portador de valores y significados culturales. Por ello, es necesario que dicho patrimonio sea experimentado para asegurar la incorporación, permanencia y vigencia de dichos valores en la identidad cultural de los usuarios. Así, una vez experimentado, constituye una práctica cultural, o hábito involucrado en la construcción, y la regularización de un rango de valores y conocimientos (Villamón, 2017, p. 126).

Sin embargo, las intervenciones realizadas hasta la actualidad no han tomado en cuenta la participación multidisciplinaria para conocer las ventajas y desventajas de modificar un inmueble histórico como es el Pabellón Central.

\section{Instituto Politécnico Nacional}

La Escuela de Ingenieros tuvo como objetivo modernizar sus estándares de enseñanza; por ello, desde sus inicios plantearon cambios que institutos con similares características ya realizaban, como es el caso de la Facultad de Ciencias Exactas, Físicas y Naturales de Buenos Aires y la Escuela de Ciencias Físicas y Matemáticas de Caracas (Rodríguez, 1999, p. 32).

Entre los esfuerzos de crear un Instituto Politécnico Autónomo, el 3 de septiembre de 1931, a través de la resolución suprema, se creó una comisión propuesta a De la Puente por Paulet. Se intentaba incluir en una gran escuela técnica a la Escuela de Ingenieros, la Escuela Nacional de Agricultura, la Escuela de Ingenieros Militares y una escuela de preparación de politécnicos. Esta idea no era nueva, y venía discutiéndose desde hacía varios años. No obstante, la propuesta no llegó a concretarse (Rodríguez, 1999). 


\section{Aspecto arquitectónico del inmueble: art déco}

El estilo art déco tuvo precedentes en Estados Unidos y Europa. Surgió a partir de la destrucción de las ciudades europeas, lo cual dejó un ambiente de penuria y crisis luego de la Primera Guerra Mundial. Durante este periodo de la posguerra fue que apareció el arte moderno, que se extendió por diversas disciplinas. Sin embargo, fue en la Exposition Internationale des Art Decoratifs et Industriels Modernes de 1925, en Francia, donde se consolidó como el inicio de un ciclo artístico. De acuerdo con Bravo (2008):

La Exposición de París de 1925 fue visitada durante el tiempo que estuvo abierta al público por más de 16 millones de personas. [...] A dicho certamen era obligado acudir con creaciones modernas y se excluían las obras historicistas y las secciones retrospectivas del pasado. [...] El jurado de la muestra de 1925 tenía la consigna de no admitir más que obras originales y nuevas que no se inspirasen en el arte pasado. (p. 17)

Las exposiciones de arte abarcaron diversas categorías, tal como lo expresa Tamayo (2010) en el libro Arquitectura en Lima 1910-1950:

El estilo art déco es un estilo internacional que surge en Francia durante los años 20 -aunque alcanza predominio en los 30 - que se extiende por el mundo rápidamente. Integrando formas abstractas y algo de la pintura constructivista como también del cubismo, termina por influir poderosamente en el diseño mundial, no solo arquitectónico sino de mobiliario, objetos decorativos y hasta de ropa. (p. 220)

En el campo de la arquitectura peruana, este estilo se distinguió de sus predecesores: «La última línea de esta etapa estaría constituida por lo que fue propiamente la gestión de la arquitectura moderna en el Perú que, como nota singular, comenzó a introducirse gradual e inofensivamente» (Martuccelli, 2000).

El contraste entre la línea sinuosa del art nouveau y la geometría del art déco fue una demostración de los cambios que ocurrieron en la época. Así lo menciona García (1980):

Por su combinación de formas decorativas modernas y composición simétrica, con ejes principales y secundarios claramente marcados, la mayor parte de la arquitectura Art- Déco puede considerarse como de transición entre los estilos académicos y la arquitectura llamada racionalista o funcionalista. Este mismo carácter transicional distingue a un grupo de numerosas obras limeñas de fines de los años treinta y primera mitad de la década de 1940. (p. 149)

El art déco, denominado como transición por García (1980), tiene diferentes puntos de vista, como el siguiente: lo que García Bryce denomina como transición no constituye propiamente un estilo, sino más bien la aplicación de una estrategia proyectual -el academicismo-, al estilo moderno (Beingolea, 2002).

El estilo art déco formó parte del inicio de la modernidad con los cambios en la arquitectura de la época. Al respecto, Beingolea (2002) manifiesta lo siguiente:

Se inicia la construcción de los edificios en altura (más de tres pisos), planteándose procedimientos más actualizados mientras la expresión está atada todavía a los principios academicistas con axialidad, simetría, la jerarquía, frontalidad, los ritmos continuos y la presencia de la decoración.

Otras características del estilo son descritas por Tamayo (2010) en el libro Arquitectura de Lima 1910-1950: «En la arquitectura se caracteriza por las formas geométricas, muchas de ellas compuestas por patrones circulares o rectas radiantes, generalmente escalonadas, bordes agudos y esquinas redondeadas, y el uso de materiales modernos» (p. 220). 


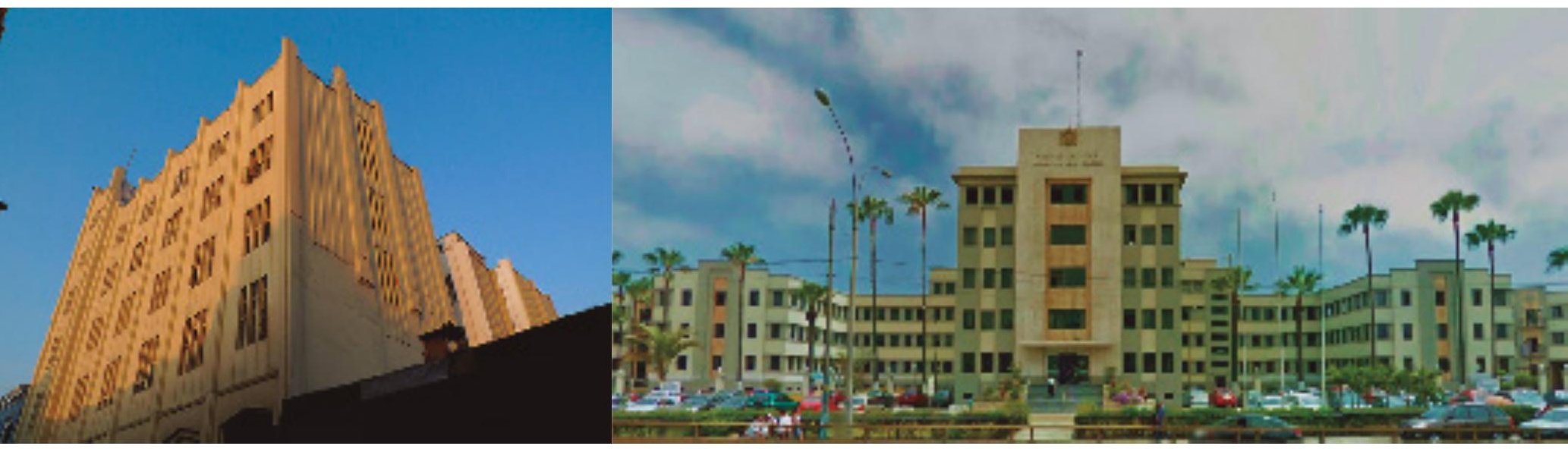

Figura 2. Arquitectura art déco en Lima. A la izquierda el edificio Gildemeister y a la derecha el edificio del Hospital Militar. Recuperado de http:// edificiogildemeister.blogspot.com/2013/09/imagenes-actuales-del-edificio.html., 2019.

En Lima, la arquitectura art déco se inicia a principios de los años treinta. Este estilo se utilizó más para viviendas de clase media que para grandes residencias y mansiones, y muchas de ellas fueron construidas en serie como casas de alquiler. Existen edificios con elementos del art déco fusionados con otros estilos, ya sean academicistas o modernistas (Villamonte, 2005).

Un ejemplo de este estilo en la capital peruana es el edificio Gildemeister, como se observa en el lado izquierdo de la Figura 2. Según Cuadra (2010), es el primer edificio de la localidad en ser denominado «rascacielos». Este tipo de construcciones contaba con cinco o seis pisos, para 1928, y fue planificado por el arquitecto alemán Werner B. Lange. En este edificio, llamaba la atención sobre todo el tratamiento expresionista de la fachada, con énfasis en la verticalidad, poco adecuado para el casco antiguo de Lima. Asimismo, Beingolea (2002) señala:

Su desarrollo es enfáticamente vertical, a la manera de los revivalistas y románticos edificios alemanes a los que sin duda remitió, mediante pilastras y elementos geométricos similares al flamante Art deco. Esa decoración vertical envuelve las caras laterales medianeras formando una envolvente decorativa. Las pilastras rematan en unos machones al nado de los cuales el parapeto de remate forma unas leves inclinaciones dando al peatón la sensación de profundidad y que la fachada no parezca alineada a la parte superior.

\section{Marco histórico}

Durante los cincuenta años posteriores a la independencia, el Perú estuvo bajo los regímenes de gobiernos militares. Esto cambió con la ocupación del cargo del primer presidente civil de la República, Manuel Pardo, entre los años 1872 a 1876. Según Mc Evoy (2013):

[...] creo que lo que hace a Pardo diferente del resto de los gobiernos anteriores es que tiene estudios. Ha estudiado Economía en Francia y ha estudiado Filosofía en España. Es un presidente que logra dominar el aspecto de las Humanidades porque entiende a los clásicos.

Este enfoque hizo que, entre sus planes, se enfatizara a la educación como fuente de cambio ante una república militarizada ya establecida. Así lo señala López (2012), en el libro Historia de la UNI: «Preocupaba a Pardo, como buen civilista, el problema educativo porque entendía que el paso de la República autoritaria a la "república práctica" de signo liberal no podía darse sin un serio incremento en los niveles educativos» (p. 4). 
Por esta razón, el principal objetivo de la época era generar una educación de calidad que cumpla con las necesidades del país. En 1875, Manuel Pardo solicita la autorización del Congreso para la creación del Reglamento General de Instrucción Pública. Con este fin, se crea una comisión encargada a los docentes de la Universidad Nacional Mayor de San Marcos (UNMSM) y a los ingenieros polacos Ladislao Folkierski y Eduardo de Habich.

Las decisiones impartidas en este reglamento estaban relacionadas con la educación superior y el mejoramiento e implantación de las áreas de Ciencias en la educación superior. Es aquí donde se toma la decisión de incorporar en el país escuelas dedicadas a la ingeniería con una orientación práctica para la formación de profesionales capacitados en la industrialización y el estudio de los recursos peruanos. Como lo expresa López (2003): «Se concreta así la idea de crear una escuela para la formación de ingenieros de minas, de construcciones civiles y de industrias, y otra para la formación de ingenieros relacionados con el trabajo agrícola» (p. 21).

Así, el 18 de marzo de 1876 fue promulgada la ley para la reforma de la educación, como se suscribe en el artículo 343 del reglamento solicitado por el presidente de la República. De esta manera, se crea la Escuela de Ingenieros.

El 23 de julio de 1876 se inauguró la Escuela Especial de Construcciones Civiles y de Minas. La ceremonia, que se celebró en el antiguo auditorio del Convictorio de San Carlos (la actual Casona de San Marcos), contó con la presencia de importantes personajes, como el presidente de la República, Manuel Pardo, al igual que el ministro de Instrucción Pública y el de Gobierno y Relaciones Exteriores. La Casona, que fue uno de los primeros recintos en alojar a la comunidad estudiantil, está ubicada en el actual distrito de Cercado de Lima y fue edificada por la Compañía de Jesús como parte de su noviciado. No obstante, uno de los problemas que afectó a la escuela, recientemente inaugurada, fue la falta de conservación de sus espacios, ya que fue creada en el siglo XVII. Estas dificultades fueron mencionadas durante el discurso de inauguración que dio el director Ing. Eduardo de Habich. Sobre este punto, en la Historia de la UNI se expresa lo siguiente:

La parte del antiguo Convictorio de Sn. Carlos destinada al uso exclusivo de la nueva escuela, en el corto tiempo de que se ha podido disponer, desde fines de junio hasta el 11 del presente en que se abrieron los cursos; a pesar de la mala estación del año y varias dificultades nacidas del estado de abandono en que se hallaba esta parte del edificio desde muchos años, se ha arreglado de un modo provisional; pero suficiente para comenzar los trabajos. (López, 2012, p. 53)

El Convictorio de San Carlos no poseía el espacio suficiente para el desempeño apropiado de la comunidad estudiantil inscrita en la escuela. Por esta razón, Eduardo de Habich envió una solicitud al Ministerio de Instrucción con la finalidad de expropiar los terrenos adyacentes para la posterior ampliación del recinto. Sin embargo, la respuesta a la petición demoró en ser respondida, por lo que Paz Soldán acepta la compra de la propiedad. Con esta nueva adquisición, se adaptaron los ambientes de la antigua construcción a las necesidades de la Escuela de Ingeniería. Para ello, se elaboró el análisis y planificación del proyecto, que estuvo a encargo del docente de arquitectura Teodoro Elmore. En Historia de la UNI, se especifican algunas conclusiones: «En opinión de Elmore, cuyos informes tienen fecha de 3 y 6 de diciembre de 1876, había que hacer una reforma casi total del local» (López, 2012, p. 74).

Es de importancia la labor que efectuaron los miembros que dirigieron la escuela y su esfuerzo por sacar adelante a dicha institución educativa. Entre ellos, resalta la labor del ingeniero polaco Eduardo de Habich, director de la institución entre 1876 a 1909. Gracias a su dirección, la escuela recaudó equipamientos de calidad provenientes de donaciones y de solicitudes enviadas a instituciones reconocidas en el Perú y el ex- 
tranjero. No obstante, las recaudaciones no eran suficientes. Es por ello que, con la autorización del general Mendiburu, la Escuela de Ingenieros utiliza los talleres de la Escuela de Artes y Oficios de Lima, en 1878, para instalar parte de las donaciones, ya que en el Convictorio carecía de espacio.

Con la continua implementación de equipamiento, la escuela se posicionó como un importante lugar dentro de la educación en el Perú. A pesar de ello, la situación que enfrentaba el país tras la declaración de guerra por parte de Chile el 5 de abril de 1879 empezó a tener consecuencias en la Escuela. Por un lado, la paralización de clases debido a que el recinto fue utilizado como parte de la defensa peruana. Pero, sin duda, lo que más afectó fue el establecimiento de las fuerzas chilenas en el local de la institución. Con la instalación chilena, se perdió la mayoría de los bienes recaudados y se deterioró la infraestructura del local.

Eduardo de Habich, alarmado por la situación, decide enviar escritos al alcalde de la ciudad de Lima y al ministro de Instrucción, para solicitar la intervención del Convictorio de San Carlos. Pese a los constantes pedidos del director de la escuela para establecer un acuerdo con la delegación chilena, estas no fueron atendidas. Ante este rechazo de las autoridades, el representante de la escuela se dirige, el 30 de mayo de 1881, al coronel chileno Demófilo Fuenzalida, quien accedió a devolver lo que quedaba en el lugar. De esta manera, el profesor de la escuela, Juan Garnier, fue el encargado de extraer el equipamiento, como documentos de la escuela, libros y los volúmenes de los anales.

El segundo local de mudanza fue el Instituto Científico, en 1881, reconocido por su educación secundaria y cuyo fundador fue José Granda. Su estadía en ese lugar terminaría en 1883, al trasladarse al Convento de Santo Domingo, ubicado en el jirón Camaná, en el Cercado de Lima, el cual fue edificado en el siglo XVI. Sin embargo, los problemas con la infraestructura por la antigüedad de sus recintos y la falta de presupuesto para el sueldo de los profesores, director y empleados salieron a la luz. La escuela se mantuvo en ese convento hasta que la ocupación chilena dejó el Convictorio de San Carlos.

El retorno al antiguo local se dio luego del trabajo de reconstrucción, pero los problemas continuaron presentándose, como lo señala López (2012):

En cuanto se reinician las clases, comienza un nutrido intercambio de oficios entre el director de la Universidad y el director de la Escuela, relativos a problemas con el agua, el gas, la luz, etc. Habich se queja, por ejemplo, de que los alumnos de la Universidad se han acostumbrado a andar por los techos de la Escuela, desde donde arrojan piedras a los alumnos de ingeniería y hacen ruidos que molestan el normal desenvolvimiento de las clases. Estos inconvenientes irán haciendo pensar a la dirección en la necesidad de buscar un local más apropiado e independiente. (p. 103)

Con los objetivos trazados por la nueva etapa que vivía el Perú, el gobierno quería demostrar a la población su preocupación por el desarrollo social a partir de la incorporación de obras públicas que generen trabajo y oportunidades. Por este motivo, la escuela vuelve a tener un lugar importante en el gobierno y busca formar a profesionales con las habilidades que demanda el país.

El cuarto local establecido fue el antiguo hospital Espíritu Santo, ocupado por la Escuela de Ingenieros entre 1889 y 1890 . Entre los problemas que trajo la ocupación de este local estuvo la antigüedad de su edificación, que requirió de costosas reparaciones. Este local, ubicado en el actual distrito de Cercado de Lima, debido a la cercanía a las zonas urbanas, expuso a esa población a la contaminación sonora y ambiental proveniente de sus laboratorios. Además, no existía el espacio necesario para una futura ampliación de las aulas, los laboratorios, los espacios deportivos, etc. Tras el aumento del alumnado, la voz de las autoridades de la escuela no se 


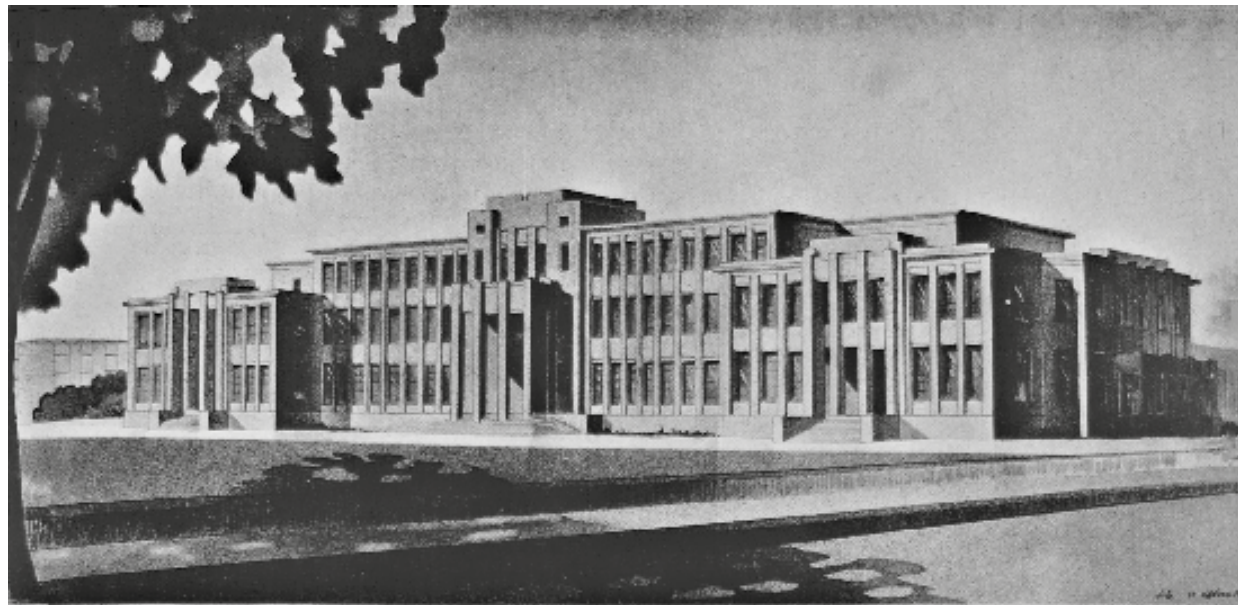

\section{ESCUELA NACIONAL DE INGENIEROS \\ GABELLOH DE ADMIHISTRACION Y AULAS.}
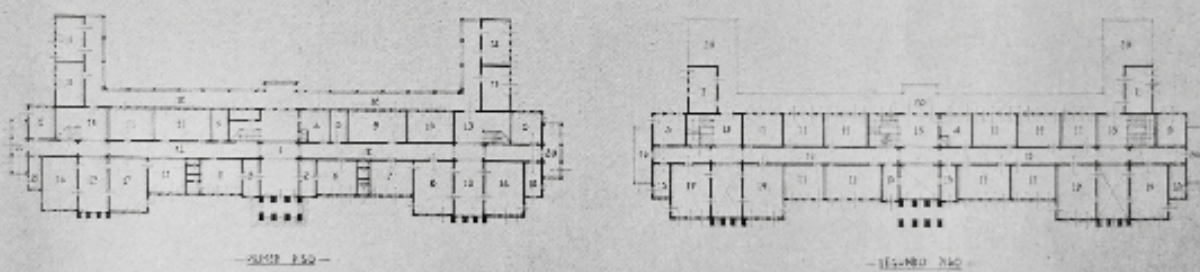

wete 132

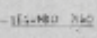

\section{-Liremes-}
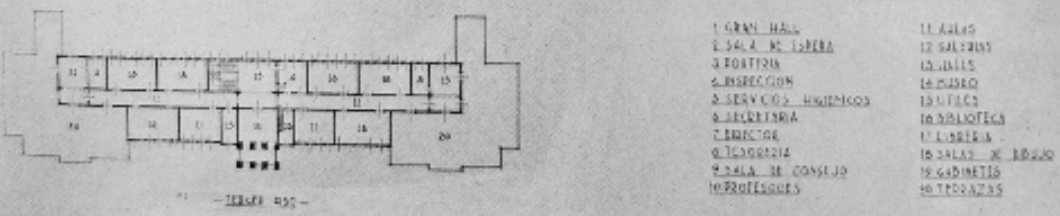

ARqTaROBERTO HAAKER FORT
Figura 3. El proyecto del edificio del Pabellón Central. En El arquitecto peruano, 1946.

LOCALES DE LA NUEVA ESCUELA DE INGENIERIA

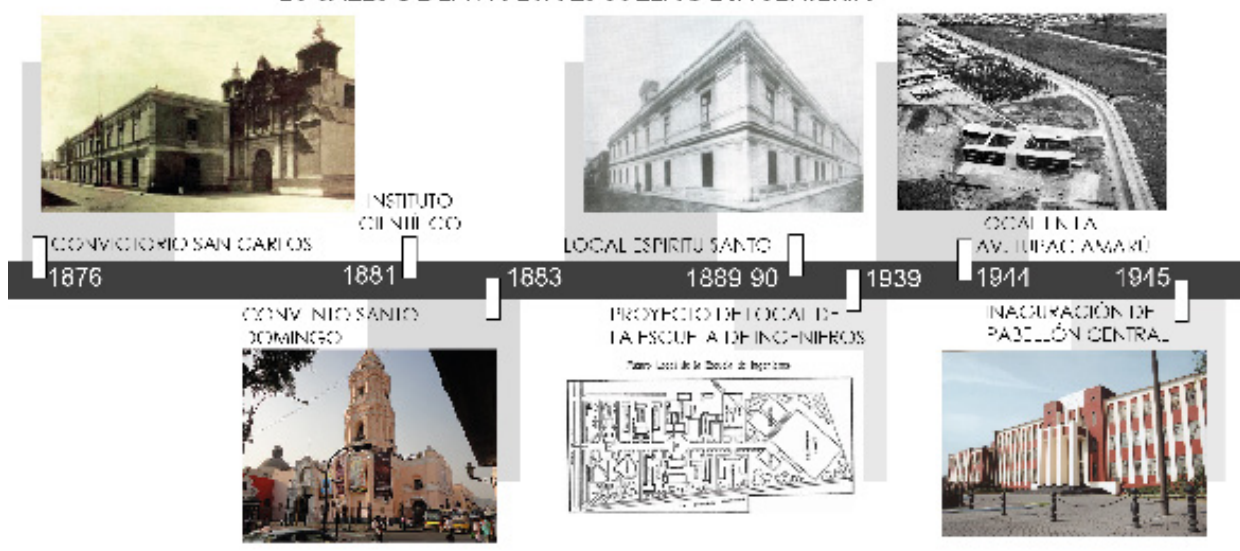

Figura 4. Línea de tiempo de los locales ocupados por la Universidad Nacional de Ingenieria. Elaboración propia, 2019. 



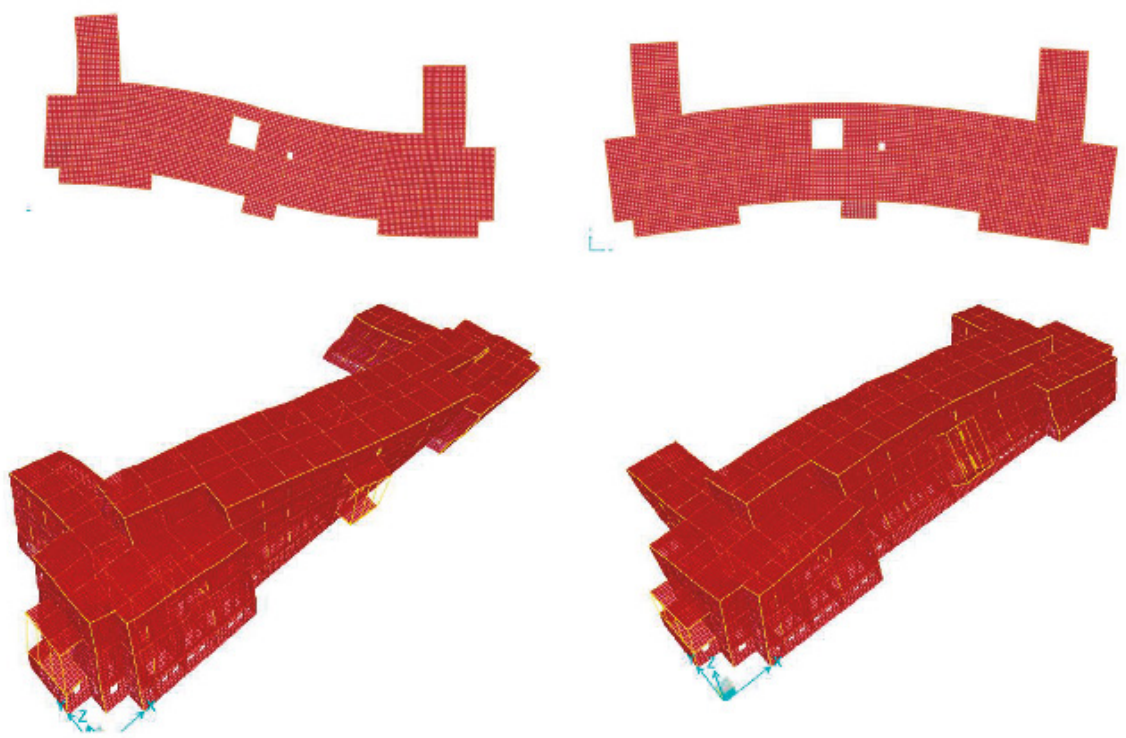

Figura 10. A la izquierda, modo predominante en la dirección longitudinal y, a la derecha modo predominante en la dirección transversal. En Centro Peruano Japonés de Investigaciones Sísmicas y Mitigación de Desastres, 2016.

Ante la antigüedad del edificio del siglo XX, se han planteado estudios relacionados con la estructura. Por ejemplo, en el año 2014 se realizó un estudio de vulnerabilidad sísmica estructural (Cismid, 2016), a partir de la instalación de sensores de aceleración. Se obtuvo, como primer diagnóstico, la existencia de debilidades en la estructura. Luego de la promulgación de la publicación de la nueva norma sismorresistente en enero de 2016, se incorporaron nuevos análisis respecto del comportamiento sísmico, mecánica de suelos y materiales. Se obtuvieron muestras de la dirección longitudinal X, paralela a la actual avenida Túpac Amaru, y Y, perpendicular a la mencionada avenida.

El diagnóstico de la evaluación demostró la presencia de sobresfuerzos en algunos de estos muros, los cuales necesitan ser reparados. Otro aspecto es la existencia de dobles alturas en el hall central, en la zona del museo y en la sala de asamblea universitaria. Al tener grandes luces y doble altura, posee mayor flexibilidad que la dirección longitudinal. Esta flexibilidad se manifiesta en la zona central del edificio, donde se deforma en planta como una viga, lo que afecta a las losas de la edificación por tener zonas con tracciones que generan los agrietamientos (Cismid, 2016) (ver Figura 10).

\section{Recomendaciones planteadas ante el estudio}

La inclusión de pórticos de arriostres excéntricos de acero en eje de la dirección transversal de la estructura, con la finalidad de disminuir la flexibilidad del edificio en su zona central y, asimismo, mejorar su comportamiento alejándolo de los límites umbrales de la norma.

Durante el proceso de inspección, se evidenció la presencia de humedad y deterioro de las líneas vitales (luz, agua y desagüe) en algunos ambientes del pabellón. Se recomienda la ejecución de un estudio de mejoramiento de las líneas vitales, ya que existen cables expuestos, llaves de cuchillas y equipos anulados no usados, pero que deben ser reemplazados. 

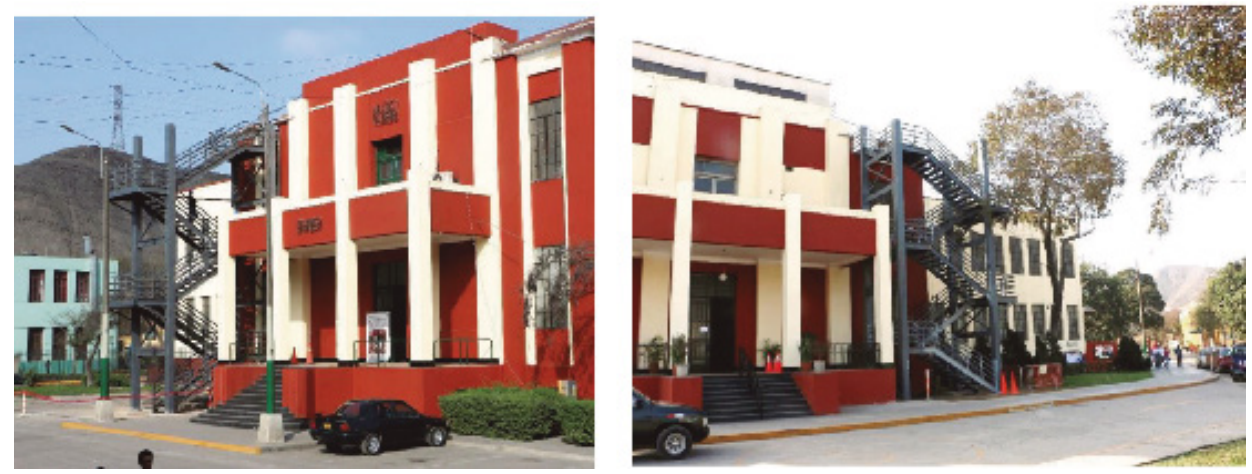

Figura 11. Modificaciones discutibles realizadas al Pabellón Central de la UNI. Archivo personal de la autora, 2019.

Es perentoria la construcción de dos escaleras de emergencia en las alas laterales del pabellón que permitan una evaluación rápida de los ocupantes del pabellón. Por esta razón, se ha incluido el diseño de dos escaleras de acero autoportantes e independientes de la estructura existente, con el objetivo de que se dote de estas vías de evacuación.

Unas zonas del sótano, en general, requieren un mantenimiento preventivo que incluya líneas vitales en adición a las acciones que se hallaron en este estudio.

Apertura al ascensor, pues contar con este elevador ayudaría al desplazamiento vertical del personal, así como a las personas de mayor edad, quienes podrían desplazarse a través de este (Cismid, 2016) (ver Figura 11).

\section{Análisis funcional}

El Pabellón Central tiene seis ingresos; existen dos entradas que son las principales establecida en el diseño, pero la que es usada como ingreso principal, en la actualidad, es la que mantiene una relación con el interior del campus universitario. Mientras que las demás se dirigen hasta determinados sectores, como zonas de uso administrativo y el Museo de Artes y Ciencia Ingeniero Eduardo de Habich (ver Figuras 12 y 13$)$.

Tiene dos ejes de simetría con un recorrido lineal de espacios de diferentes tamaños, formas y funciones. Cuenta con cuatro niveles con una altura estimada de cinco metros y un semisótano que se conecta verticalmente con los niveles a través de una escalera. Además, tiene un ascensor que no se encuentra en funcionamiento. Como se menciona en el Boletín de la Escuela de Ingenieros:

El edificio consta de un sótano de 3,300 metros cuadrados; planta baja con 3,600 metros cuadrados segundo piso de 2,544 metros cuadrados; el tercero con 1,152 metros cuadrados más un cuarto piso de 144 metros cuadrados. En total 10,744 metros cuadrados de construcción.

El sótano está destinado a depósito y diversos talleres; en la planta baja funcionará: la Dirección, la Administración, Biblioteca y algunas aulas: el segundo y el tercer piso están destinados exclusivamente a aulas: el cuarto para diversos servicios. Completan el edificio varios halls, amplias galerías de circulación y tres cómodas escaleras además de un ascensor (UNI, 1945, p. 8) 


\section{PLANIMETRIA}

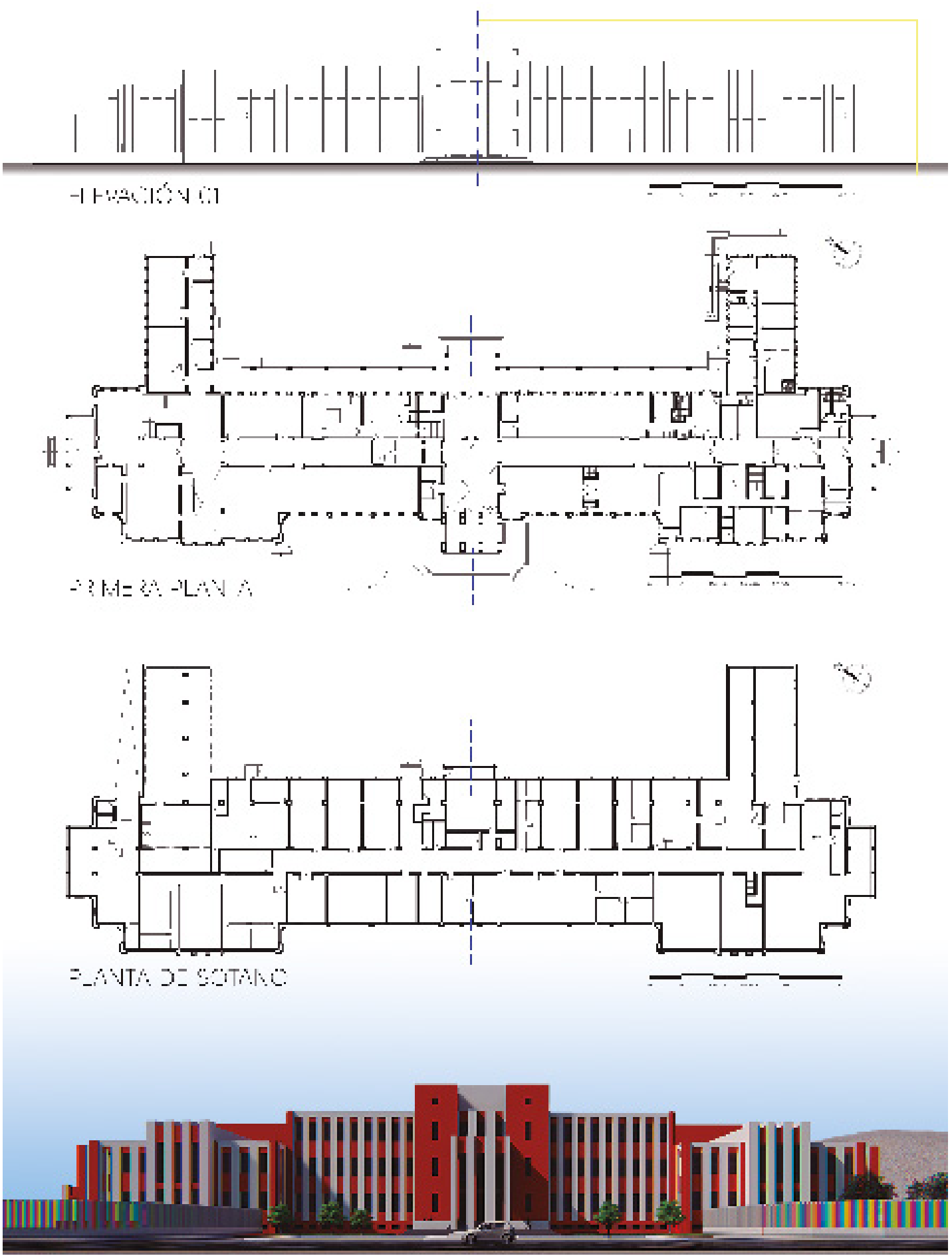

Figura 12. Planimetrías y fachada frontal del Pabellón Central. Modificado por Sandra Salazar a partir de los planos proporcionados por la Oficina de Patrimonio UNI y SketchUP, 2019. 


\section{PLAMIIMETFiA}

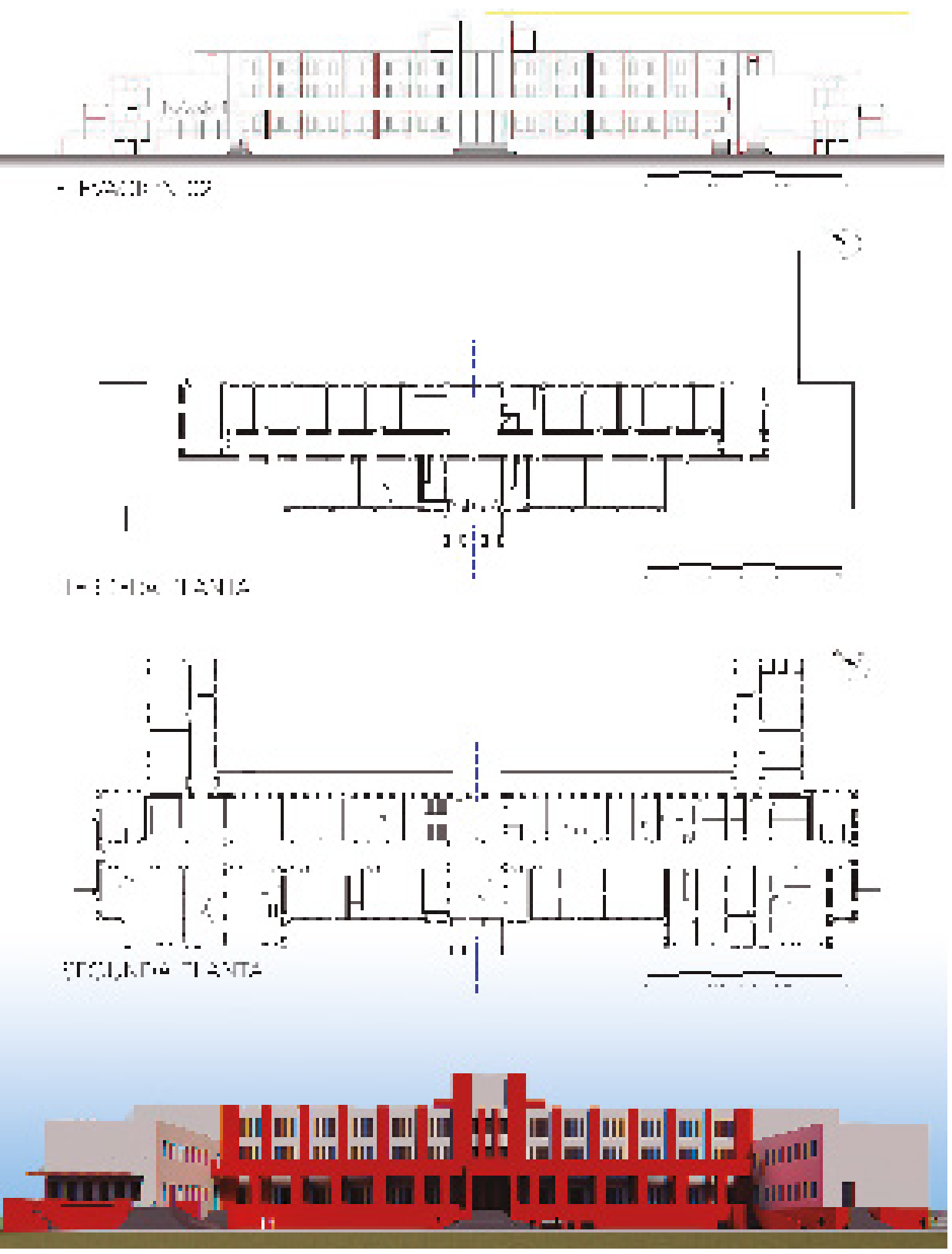

Figura 13. Planimetrías y fachada posterior del Pabellón Central. Modificado por Sandra Salazar a partir de los planos proporcionados por la Oficina de Patrimonio UNI y SketchUP, 2019.

\section{Análisis simbólico}

El valor es entendido en sus diferentes acepciones como el «grado de utilidad o aptitud de las cosas, para satisfacer las necesidades o proporcionar bienestar o deleite [...] Alcance de la significación o importancia de una cosa, acción, palabra o frase» (Hayakawa, 2012, p. 2) (ver Figura 14). 
¿Qué actividad usted desempeña en la universidad?

\begin{tabular}{|c|c|c|c|c|c|c|c|c|}
\hline \multirow{3}{*}{ Visitante } & I & I & I & I & I & I & I & I \\
\hline & 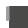 & I & I & | & I & I & I & I \\
\hline & & I & I & | & I & I & I & I \\
\hline \multirow{3}{*}{ Trabajador } & I & I & I & I & I & I & $\mathbf{I}$ & I \\
\hline & 4 & 1 & 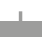 & - & 1 & 1 & I & I \\
\hline & 1 & & & 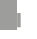 & 1 & 1 & 1 & I \\
\hline \multirow{4}{*}{ Estudiante } & I & I & I & I & I & I & I & I \\
\hline & I & I & I & I & I & I & I & I \\
\hline & 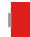 & I & I & 1 & 1 & I & 1 & 1 \\
\hline & 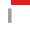 & I & I & I & I & I & I & I \\
\hline \multirow{5}{*}{ Docente } & I & I & I & I & I & I & I & I \\
\hline & 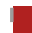 & I & I & I & I & I & 1 & I \\
\hline & & I & I & I & I & I & I & I \\
\hline & I & I & I & I & I & I & I & I \\
\hline & 0 & 5 & 10 & 15 & 20 & 25 & 30 & 35 \\
\hline
\end{tabular}

Figura 14. Desempeño de los encuestados. Elaboración de Sandra Salazar sobre la base de entrevistas, 2019.

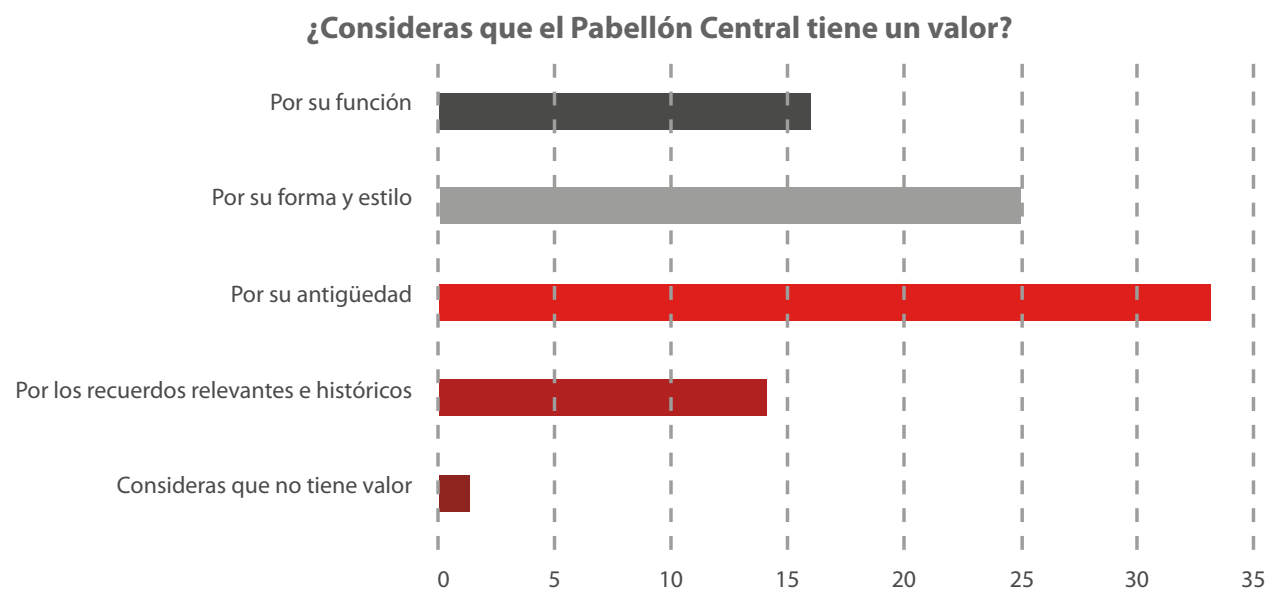

Figura 15. Valoración del Pabellón Central. Elaboración de Sandra Salazar sobre la base de entrevistas, 2019.

Como parte de la investigación, se elaboró un cuestionario que tiene como referencia a Pajuelo (2016, p. 138), pero en este caso fue aplicado a los estudiantes de la UNI, trabajadores del Pabellón Central y a los profesionales en temas patrimoniales. A continuación, se conocerán los resultados de la encuesta (ver Figura 15).

Como se muestra en la Figura 15, el 97,8 \% de los encuestados considera que sí tiene un valor. El $32 \%$ de los encuestados estima que tiene un valor por su antigüedad; el $23 \%$, por su forma y estilo; el $13 \%$, por los recuerdos relevantes e históricos; el $14 \%$, por su función; y el 2,2 \% considera que no tiene valor (ver Figura 16).

Por otro lado, el valor otorgado de los encuestados con respecto a las razones por las cuales debería conservarse el Pabellón Central son las siguientes: conservarse por su forma y estilo, el 26,1 \%; por considerarlo patrimonio histórico-cultural, el 58,7\%; porque es un recuerdo, el 11,1\%; y el 2,2 \% considera que tiene que conservarse (ver Figura 17).

En el Pabellón central, se desempeñan actividades administrativas en un mayor porcentaje en comparación con las actividades culturales, como se muestra en la Figura 17. El $91,1 \%$ son servicios administrativos, el $35,6 \%$ son talleres y charlas, y el $60 \%$ son actividades de cultura-educación.

Ante la pregunta que evalúa la satisfacción del uso actual de la edificación que se muestra en la Figura18, existe una aprobación del 65,8 \%; el 29,8 \% están insatisfechos 
devenir Vol.6, N¹2, JULIO-DICIEMBRE 2019, PP. 115-136 - EstUdIOS I ISSN 2312-7562 | E-ISSN 2616-4949 UNIVERSIDAD NACIONAL DE INGENIERÍA, LIMA

doi: https://doi.org/10.21754/devenir.v6i12.746

¿Por qué consideras que debe conservarse el Pabellón Central?

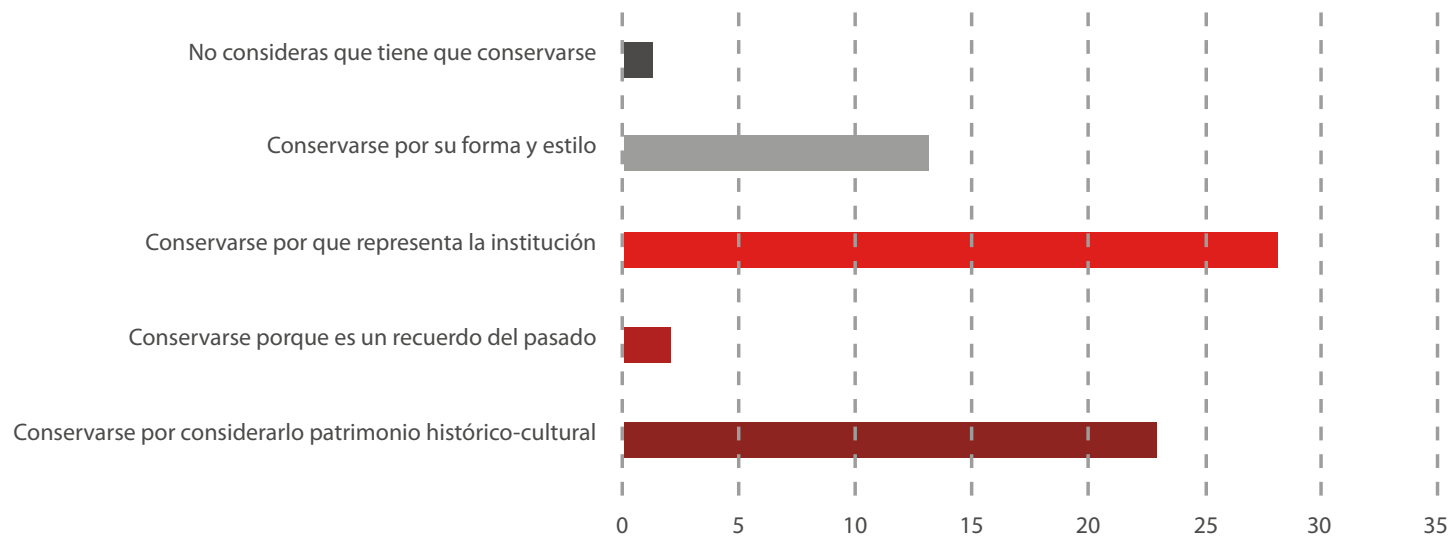

Figura 16. Conservación del Pabellón Central. Elaboración de Sandra Salazar sobre la base de entrevistas.

¿Cuáles son las actividades que se desempeñan en la actualidad en el Pabellón Central?

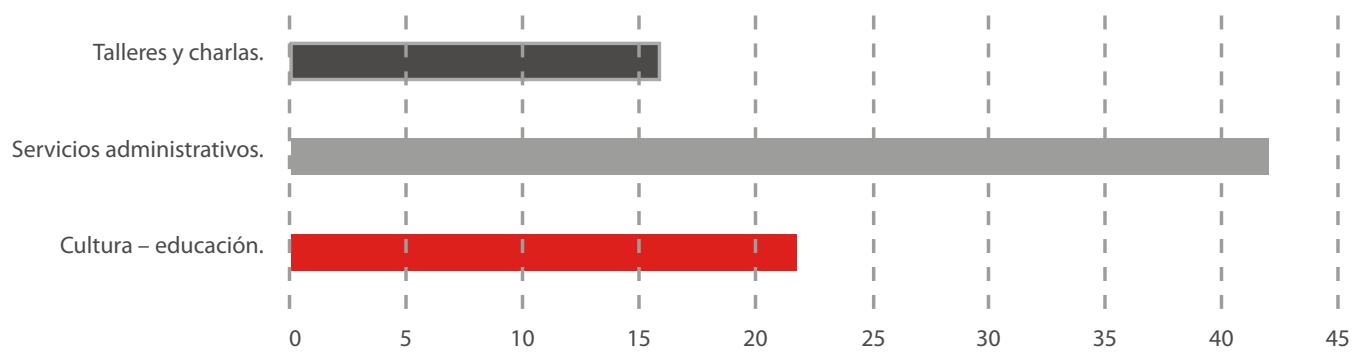

Figura 17. Actividades del Pabellón Central. Elaboración de Sandra Salazar sobre la base de entrevistas.

¿Qué tan satisfecho se encuentra con el uso actual del Pabellón Central?

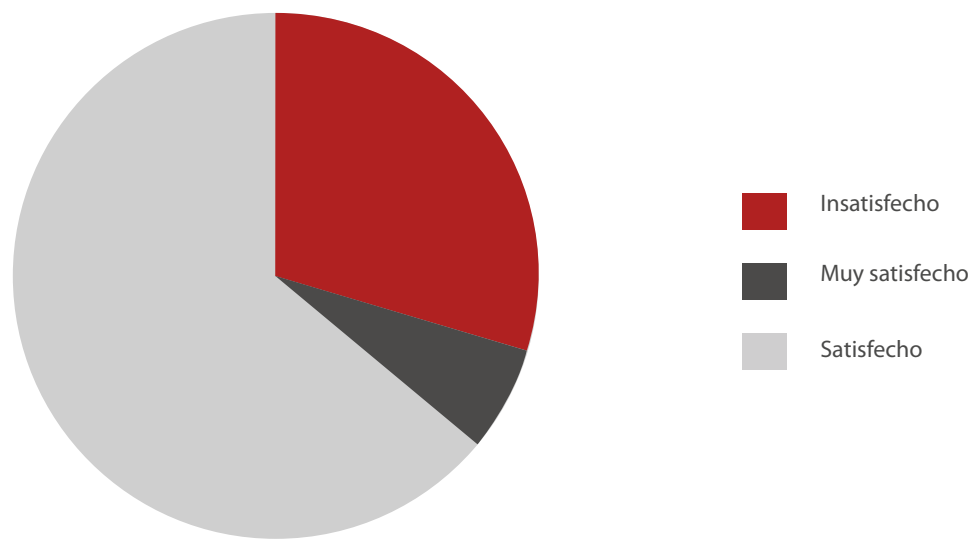

Figura 18. Satisfacción en cuanto al uso del Pabellón Central. Elaboración propia. Adaptado de Google Maps, 2019. 
y el 4,4 \% están muy insatisfechos. A pesar de que existe un gran porcentaje que está de acuerdo con las funciones actuales, hubo comentarios como los siguientes:

- Los nuevos requerimientos institucionales hacen que la UNI pida con urgencia un nuevo Pabellón Central, y el que tenemos ahora debería transformase en El Gran Museo de Lima Norte. (Encuestado, 25 de junio de 2019)

- Podría tener más relación con los alumnos y el parque de enfrente, como se planteó en una propuesta del concurso de escaleras del Pabellón Central en el que los techos eran usados como terrazas para actividades lúdicas. También, ya que hay un museo dentro, se podrían hacer recorridos guiados por las instalaciones del edificio para explicar su historia y valor arquitectónico. (Encuestado, 25 de junio de 2019)

- Que los egresados de la UNI puedan concursar en ideas de proyecto, convenios con instituciones de música, que pueda abrirse consultorías dentro de la UNI y ahí empiecen a realizar sus prácticas los estudiantes de la UNI, dado que tenemos mucha capacidad para realizarlo, y se cobraría más barato y tendría mayor mercado, dado que la UNI es muy reconocida (me refiero, por ejemplo, a estudios eléctricos, diseño electromecánico). (Encuestado, 25 de junio de 2019)

- Como en las grandes universidades, debería tener una puerta de ingreso principal de la comunidad universitaria, ya que, por su envergadura, simetría, escalones, columnas, puertas de ingreso y su representación histórica de la UNI, le da un mayor significado a la institución. (Encuestado, 25 de junio 2019)

Esta encuesta ha permitido conocer los puntos de vista de los participantes de la encuesta y cómo consideran que el edificio forma parte de su cotidianidad. Incluso, muchos de ellos opinan que el cambio de uso a actividades culturales mejoraría la imagen de la edificación y su estadía en el campus universitario.

\section{Análisis formal espacial}

El Pabellón Central es un edificio de claro estilo art déco. Tiene una volumetría sólida de la que surgen dos cuerpos perpendiculares al volumen central, ubicados en los extremos noreste y suroeste, lo que le da la forma de U. Los elementos geométricos y el escalonamiento de los volúmenes decoran la fachada, que no posee mayor ornamento.

Cuenta con cuatro fachadas. La fachada principal es la que se ubica hacia el sureste y cuenta con un retiro hacia la avenida Túpac Amaru. En este sector, se encuentra el ingreso destinado en el diseño para el inmueble, remarcado a través de una sección central que sobresale del parámetro plano, al cual se accede por una escalinata hacia el vestíbulo de doble altura. En todo el edificio se buscó tener una expresión sobria y sin ornamentos clásicos mediante el uso de líneas rectas y elementos geométricos. Al ser una edificación institucional, se busca acentuar la altura con el uso de machones o estructuras verticales, lo que logra unificar los niveles. Si bien se distinguen las divisiones de los niveles por medio de los elementos no estructurales, estos también contribuyen con la verticalidad, como se muestra en las ventanas rectangulares cuya menor dimensión está orientada al lado horizontal.

Al noreste, igual que en la fachada principal, son las de mayores dimensiones. En este caso, se tiene un patio que se forma por la volumetría del edificio. Se accede a través de una escalinata hasta llegar a un balcón corrido, ubicado en el primer nivel. En el segundo nivel, aparece un balcón en el vestíbulo de entrada.

Las localizadas al noreste y noroeste tienen menores dimensiones. Además, son similares entre sí, ya que es un edificio simétrico y cada una cuenta con un balcón en el segundo nivel (ver Figura 19). 


\section{AHALLIEIS FORMAL}

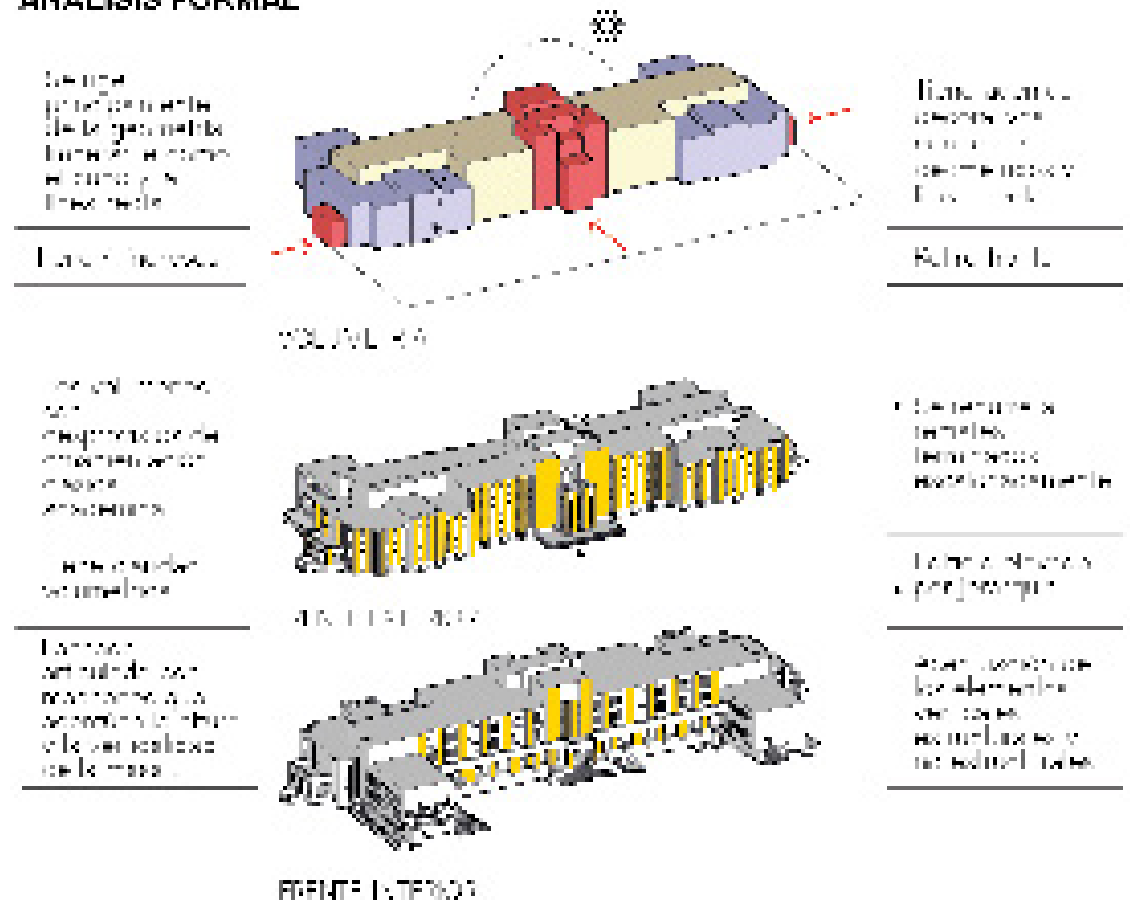

Figura 19. Análisis formal del edificio del Pabellón Central. Adaptado de https://issuu.com/arquitecturaperuana/docs/museo_de_las_artes_y_ciencias_ingen

\section{Reflexiones finales}

La UNI alberga un valor en los diversos aspectos que la conforman. Si bien es reconocida por su capacidad en la formación de profesionales en el campo de la ingeniería y la arquitectura, también cuenta con un conjunto patrimonial de distintas épocas. Cuando se adquirió el nuevo local en los terrenos del fundo Puente Palo, este ya contaba con monumentos arqueológicos en distintas áreas dentro su perímetro. Al mismo tiempo, la Escuela de Ingenieros llegó a ocuparlo luego de una larga búsqueda por un espacio donde desempeñar sus funciones de forma más eficiente. Es aquí donde se construye el primer edificio, con la colaboración de muchos agentes, pero sobre todo con el orgullo de ver uno de sus objetivos cumplidos. La importancia de valorar estos sucesos radica en el manejo y cuidado que se les dé a través del tiempo. Otro punto importante, dentro de este contexto, es que el correcto uso del patrimonio también genera un reconocimiento del entorno social y un aporte económico que puede ayudar a ser autosostenible. Los trabajos y la gestión que se ejecuten en la defensa de este patrimonio contribuirían en su reconocimiento como patrimonio material inmueble por el Ministerio de Cultura.

Difundir la importancia histórica y arquitectónica del Pabellón Central contribuye con eliminar muchas interrogantes de los alumnos, e incluso de los trabajadores de la propia universidad, sobre el origen de esta edificación. A través de este artículo, se desmienten algunas ideas creadas y sostenidas por mucho tiempo. Por ejemplo, pensar que en determinado momento funcionó como un hospital, por la altura de sus niveles o el ancho de sus pasadizos principales. Como se observa en la Figura 3, referente a la publicación de la revista El arquitecto peruano, este edificio, desde su presentación como proyecto, fue destinado para las funciones administrativas. 


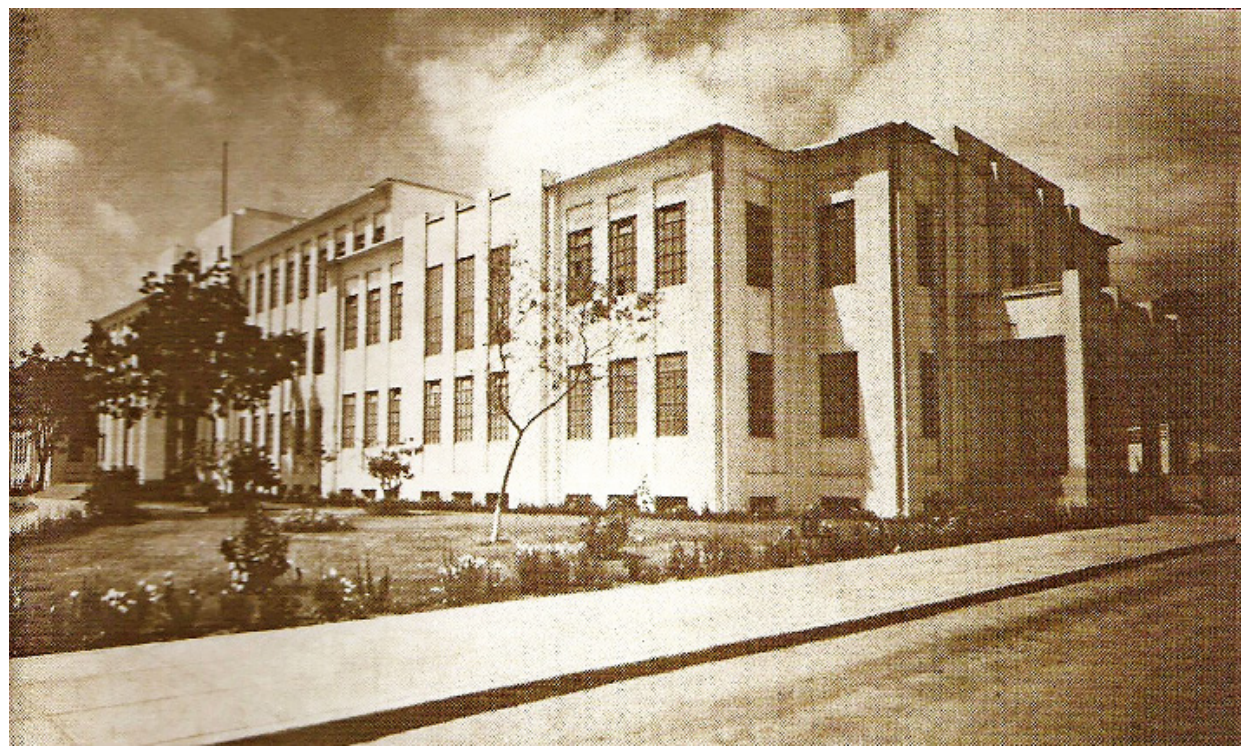

Figura 20. Vista lateral del Pabellón Central tomada a la altura de la actual puerta 3. Recuperado de http:// arqcabello.blogspot.com/search/label/fotograf\%C3\%ADas

A través del análisis estructural, se comprobó la calidad de los materiales empleados para la construcción del Pabellón Central, además de los estudios realizados por el Cismid durante el 2014 y el 2016 con el objetivo de determinar las fallas y plantear soluciones desde su campo. Sin embargo, al ser una edificación de 1945, tiene ciertas características propias del estilo art déco que se deben tomar en cuenta frente a alguna intervención. Un claro ejemplo de las diversas variaciones ocurridas en esta construcción es la incorporación de dos escaleras de escape de forma arbitraria y sin la evaluación de un diseño que logre integrarlas al conjunto. Otro punto que resaltar es la capacidad de carga que soporta por las actividades que se desarrollan en su interior. Plantear un trabajo multidisciplinario para cubrir las necesidades que aparecen a causa de la antigüedad del Pabellón Central debería ser discutido para llegar a un acuerdo antes de realizar intervenciones independientes.

La creación del Museo de Artes y Ciencia Ingeniero Eduardo de Habich es una buena iniciativa que permite defender su patrimonio y difundirlo mediante las actividades que se realizan en sus instalaciones. Esto debería ser replicado en su conjunto cubriendo distintas actividades que se relacionen entre sí. El Proyecto Integral de Restauración de la Casona de San Marcos y la adecuación a uso como Centro Cultural efectuado por el arquitecto Martín Fabbri. Como lo expresa Gambetta (2018):

Este proyecto, iniciado en marzo del año 1992, fue llevado a cabo gracias a un convenio de cooperación entre la Universidad Nacional de San Marcos de Lima (UNMSM) y la Agencia Española de Cooperación Internacional para el Desarrollo (AECID). Tuvo una duración de alrededor de 20 años, durante los cuales se realizaron labores para revertir el estado lamentable de deterioro en el que se encontraba el edificio, que estaba en peligro de ser demolidos. (p. 20)

Esto puede ser considerado como un ejemplo de los beneficios que producen ciertos cambios ante la valoración del patrimonio existente.

La información recolectada en esta investigación del Pabellón Central de la UNI permite conocer y valorar las diversas cualidades que tiene el edificio (ver Figura 20). 
devenir Vol.6, N¹2, JULIO-DICIEMBRE 2019, PP. 115-136 - EstUdIOS I ISSN 2312-7562 | E-ISSN 2616-4949

UNIVERSIDAD NACIONAL DE INGENIERÍA, LIMA

doi: https://doi.org/10.21754/devenir.v6i12.746

\section{Referencias}

Beingolea, J. (2002). Arqandina. Recuperado de http://www.arqandina.com/

Bravo, A. (2008). Arquitecturas Art Déco en el Mediterráneo: I Congreso internacional Ciudad y Patrimonio, Art Déco, modelos de modernidad = I Congreso international Ville et Patrimoine, Art Déco, modèles de la modernité. Barcelona, España: Stylos.

Cismid. (2016). Especificaciones técnicas de las intervenciones y mantenimientos edificio del Pabellón Central de la Universidad Nacional de Ingeniería. Lima. Universidad Nacional de Ingeniería.

Cuadra, M. (2010). Arquitectura en América Latina: Perú, Bolivia, Ecuador y Chile en los siglos XIX y $X X$. Lima, Perú: Universidad Nacional de Ingeniería.

Gambetta, M. (2018). Evolución del enfoque de conservación y restauración del patrimonio edificado: la experiencia de Martin Fabbri en Perú. Devenir. Revista de estudios sobre el patrimonio edificado, 5(10), 11-28.

García, J. (1980). Historia del Perú. Lima. Perú: Juan Mejía Baca.

Gavazzi, A. (22 de setiembre de 2017). La planificación prehispánica de Lima [archivo de video]. Recuperado de https://www.youtube.com/watch?v=Gbj1AuvTCeM\&t=314s

Guzmán, E. (2015). Huacas de la Universidad Nacional de ingeniería y la verdadera Huaca Aliaga. Devenir. Revista de estudios sobre el patrimonio edificado, 2(4), 104-126.

Hayakawa, J. (2012). Restauro UNI. Breve antología de textos de restauración del patrimonio. Lima, Perú: Fondo Editorial de la UNI.

Martuccelli, E. (2000). Arquitectura para una cuidad fragmentada. Lima, Perú: Universidad Ricardo Palma.

Mc Evoy, C. (30 de setiembre de 2013). Sucedió en el Perú - Presidentes del Perú Siglo XIX 3/5 [archivo de video]. Recuperado de https://www.youtube.com/watch?v=2JrxpyWQ9Zo

Nieto Pérez, C. (2018). La apropiación social del patrimonio como elemento de prevención en la salvaguarda de los bienes culturales apropiación social del patrimonio como elemento de prevención en la salvaguarda de los bienes culturales [Tesis doctoral inédita]. Universitat Politècnica de València, España. DOI:10.4995/Thesis/10251/106964

López, J. (2003). Breve historia UNI. Lima: EDUNI.

López, J. (2003). Historia de la Univerdad Nacional de Ingenieria. Tomo II. Los años de fundación. (1876-1909). Lima: EDUNI.

Pajuelo, R. (2016). La recuperación participativa de la historia y la memoria para el uso social del patrimonio huarochirano: El caso del ex centro educativo $N^{\circ} 443$. Devenir. Revista de estudios sobre el patrimonio edificado, 3(6), 125-142.

Rodríguez, K. (1999). Historia de la Universidad Nacional de Ingenieria. Tomo III. La apertura de nuevos espacios. (1930-1955). Lima: EDUNI .

Salazar, S. (2017). Museo de las Artes y Ciencia Ingeniero Eduardo de Habich. Lima: Arquitectura Peruana. Recuperado de https://issuu.com/arquitecturaperuana/docs/museo_de_las_artes_y_ciencias_ingen

Silva, A. (2006). Imaginarios Urbanos. Bogotá: Arango.

Tamayo, A. (2010). Arquitectura de Lima 1910 - 1950. Lima: ARGOS.

Universidad Nacional de Ingeniería. (1945). Boletin de la Escuela Nacional de Ingenieros. Lima: Eduni.

Villamón, T. (2017). Reflexiones teóricas contemporáneas sobre el patrimonio edificado y su significado. Devenir. Revista de estudios sobre el patrimonio edificado, 4(8), 123-133.

Villamonte, G. (2005). Arquitectura y representación ideológica en Lima del siglo XX: Los edificios gubernamentales construidos durante el Gobierno Revolucionario de las Fuerzas Armadas (19681975) [Tesis de licenciatura]. Recuperado de http://tesis.pucp.edu.pe/repositorio/ 